\title{
As contribuições do professor universitário para o engagement acadêmico
}

\author{
Emili Rossi \\ Universidade Federal da Fronteira Sul, Erechim, RS, Brasil \\ Zoraia Aguiar Bittencourtii \\ Universidade Federal da Fronteira Sul, Erechim, RS, Brasil
}

Fernanda Figueira Marquezan Universidade Franciscana, Santa Maria, RS, Brasil

\begin{abstract}
Resumo
A pesquisa objetivou compreender como o professor universitário contribui para o engagement acadêmico no curso de Pedagogia da Universidade Federal da Fronteira Sul, campus Erechim, Rio Grande do Sul, na perspectiva de estudantes do curso. Para tal, foram entregues 139 questionários a estudantes de diferentes semestres do curso contendo perguntas relacionadas à identificação do perfil dos professores e de aulas que atraem e envolvem os estudantes. Os resultados foram divididos em duas categorias - (I) Características e práticas docentes valorizadas pelos estudantes e (II) Projeções dos estudantes para seus futuros profissionais - e analisados pela perspectiva da Análise de Conteúdo, de Bardin (2016). Conclui-se que as contribuições dos professores para o engagement estudantil se dão por meio de propostas de aprendizagem ativa, vivências significativas e uma relação de confiança e segurança entre professor e alunos. Por fim, considerando a ausência de instrumentos brasileiros para avaliar o engagement acadêmico, são apresentados possíveis indicadores de como instrumentalizar esta avaliação.
\end{abstract}

Palavras-chave

Educação Superior. Engagement acadêmico. Aprendizagem. Professor universitário.

\section{Contributions of lecturers for the academic engagement}

\begin{abstract}
The research aimed at understanding to what extent the professor helps the academic engagement in the Pedagogy Course from Federal University of Fronteira Sul, campus Erechim, Rio Grande do Sul, from the students' perspective. For such, 139 questionnaires with questions relating to the identification of professors' and lessons' profiles that attract and engage more students, were given to students from different semesters of the course. Results were divided into two categories: (I) teachers' characteristics and practices appreciated by students and (II) students' projections for their professional future. The results were analyzed by the Content Analysis from Bardin (2016). It is concluded that the contributions of professors for the academic engagement are by means of active learning proposals, meaningful experiences and a relation of confidence and reliability between professor and student. To conclude, considering the
\end{abstract}


lack of Brazilian tools to evaluate the academic engagement, we present possible indicators of how instrumentalizing this evaluation.

\title{
Keywords
}

Higher education. Academic engagement. Learning. Lecturer.

\section{Las contribuciones del profesor universitario para el engagement académico}

\begin{abstract}
Resumen
La investigación objetivó comprender como el profesor universitario contribuye para el engagement académico en el curso de Pedagogía de la Universidade Federal da Fronteira Sul, campus Erechim, Rio Grande do Sul, en la perspectiva de estudiantes del curso. Para tal, fueron repartidos 139 cuestionarios a estudiantes de diferentes semestres del curso conteniendo preguntas relacionadas a la identificación del perfil de los profesores y de clases que atraen y cautivan a los estudiantes. Los resultados fueron divididos en dos categorías - (I) Características y prácticas docentes valoradas por los estudiantes y (II) Proyecciones de los estudiantes para sus futuros profesionales - y analizados desde la perspectiva del Análisis de Contenido, de Bardin (2016). Se concluye que las contribuciones de los profesores para el engagement estudiantil se dan por medio de propuestas de aprendizaje activa, vivencias significativas y una relación de confianza y seguridad entre profesor y alumnos. Por fin, teniendo en cuenta la ausencia de instrumentos brasileños para evaluar el engagement académico, son presentados posibles indicadores de como instrumentalizar esta evaluación.
\end{abstract}

\section{Palabras clave}

Educación superior. Engagement académico. Aprendizaje. Profesor universitario.

\section{Introdução}

O engagement na Educação Superior é um tema crescente nas pesquisas dos últimos anos. Engagement acadêmico, nesta pesquisa, é tratado como um "[...] processo que envolve múltiplos aspectos (afetivos, cognitivos e comportamentais), que, quando mobilizados, permitem o envolvimento efetivo dos estudantes com o meio e com as atividades acadêmicas" (VITÓRIA et al., 2018, p. 263). Nesse sentido, o objetivo deste estudo foi compreender como o professor contribui para o engagement acadêmico no Curso de Pedagogia da Universidade Federal da Fronteira Sul (UFFS), campus Erechim/RS, na perspectiva de estudantes do curso.

Sendo assim, a relação professor-aluno precisou ser analisada mais detidamente. Paulo Freire (2011), patrono da Educação Brasileira, diz que, como educador, deve-se romper a dicotomia entre seriedade docente e afetividade. Abrir-se para querer bem os estudantes não exclui a seriedade docente, mas sim mostra que não 
só dela é feita uma relação. Ensinar, ainda segundo Freire (2011), é uma prática específica do ser humano e, sendo humana, envolve aspectos que estão além da transmissão do conhecimento científico, inclusive na universidade. Em muitos casos, é possível afirmar, sem correr risco do exagero, que o professor determina permanentemente a ideia que o aluno desenvolverá sobre determinada área do conhecimento ou objeto de estudo.

Tal importância motivou esta pesquisa a ir em busca dos fatores que condicionam a aprendizagem, o envolvimento, o engajamento, os processos identificatórios, sobretudo na universidade, dos alunos com seu curso e sua futura profissão. Neste caminho, certamente estão os "bons" professores.

Para definir o que caracteriza um bom professor, McEwan (2002) elenca dez características que desenham o bom professor. Essas dez características são agrupadas em: traços pessoais, traços referentes aos resultados pretendidos e traços da vida intelectual. Pode-se prever que, diante dessas qualidades, o professor consiga construir e manter uma boa relação com os alunos, frutificando em qualidade de desempenho acadêmico, bem como identificação com a futura profissão.

Diante disso, a pesquisa foi em busca de compreender quais características e práticas são valorizadas pelos acadêmicos em seus professores, uma vez que esses aspectos compõem o processo de engagement estudantil na Educação Superior. Segundo Vitória et al. (2018), há três dimensões que envolvem o processo de engagement: a dimensão afetiva, a dimensão cognitiva e a dimensão comportamental, e todas elas têm relação direta com o professor. Para atingir tal objetivo, realizou-se uma pesquisa de campo com entrega de questionários a estudantes de todos os semestres do curso de Pedagogia da UFFS/Erechim com questões referentes a aspectos que circundam suas trajetórias acadêmicas, mais detidamente a respeito da atuação e influência dos professores nesse processo.

\section{Metodologia}

A pesquisa realizada utilizou uma abordagem qualitativa (LÜDKE; ANDRÉ, 2017), uma vez que seu foco foi a intencionalidade presente nos dados coletados. A primeira etapa constituiu-se de uma pesquisa bibliográfica. Esta metodologia "[...] implica 
em um conjunto ordenado de procedimentos de busca por soluções, atento ao objeto de estudo, e que, por isso, não pode ser aleatório" (LIMA; MIOTO, 2007, p. 38).

Após a pesquisa bibliográfica, a fim de responder ao objetivo de compreender como o professor contribui para o engagement acadêmico no curso de Pedagogia da UFFS, campus Erechim, Rio Grande do Sul (RS), na perspectiva de estudantes do curso, foi necessário conhecer as ideias formadas pelos discentes sobre seus professores universitários. Esse levantamento foi feito por meio da entrega de questionário. Gil (2008, p. 121) define questionário como "[...] conjunto de questões que são submetidas a pessoas com o propósito de obter informações sobre conhecimentos, crenças, sentimentos, valores, interesses, expectativas, aspirações, temores, comportamento presente ou passado etc.".

Desse modo, participaram da pesquisa 139 estudantes do curso de licenciatura em Pedagogia. Foram contempladas todas as turmas do curso, totalizando cinco turmas. Os participantes da pesquisa têm entre 18 e 69 anos, estudantes de escola pública em sua maioria e advindos de variadas regiões do Brasil, principalmente do Sul. Antes de responder ao questionário, os sujeitos da pesquisa receberam um Termo de Consentimento Informado, no qual ficou declarado que suas respostas poderiam ser utilizadas nesta pesquisa, desde que suas identidades fossem preservadas.

A etapa seguinte foi a análise dos dados, apoiada na Análise de Conteúdo, de Bardin (2016). Esta metodologia é dividida em três etapas: 1) Pré-análise: consiste num período organizacional, no qual é definido o material a ser submetido à análise, neste caso os questionários; as hipóteses sobre os resultados a serem obtidos; o objetivo ao qual se propõe chegar analisando as respostas; e a categorização de elementos essenciais que fundamentem a interpretação final; 2) Exploração do material: corresponde à aplicação propriamente dita dos termos definidos na pré-análise; 3) Tratamento dos resultados obtidos e interpretação: após o material já ser explorado, o seguinte passo é analisar os resultados, podendo gerar gráficos, diagramas, quadros, figuras, de acordo com os elementos fundamentais extraídos e, por fim, interpretar os dados a fim de confirmar ou refutar as hipóteses iniciais ou criar novos vieses de análise.

Ademais, foi feita a construção de duas categorias descritivas (LÜDKE; ANDRÉ, 2017). Para Bardin (2016, p. 148), “[...] classificar elementos em categorias impõe a 
investigação do que cada um deles tem em comum com outros. O que vai permitir o seu agrupamento é a parte comum existente entre eles". Portanto, essas categorias descritivas fizeram alusão aos principais aspectos apontados nos questionários, seja por maior incidência de palavras ou frases, por grau de significância ou por temáticas. As categorias construídas para a análise de dados foram: (I) Características e práticas docentes valorizadas pelos estudantes e (II) Projeções dos estudantes para seus futuros profissionais.

\section{Resultados e discussão}

Observando todas essas premissas, foi coletado um total de 139 questionários, os quais contavam com perguntas objetivas e subjetivas em relação: I) aos motivos pelos quais escolheram cursar licenciatura em Pedagogia; II) à fase do curso na qual se encontravam; III) à área de atuação com que têm se identificado mais e por quê; IV) às características que consideram importantes ao professor universitário; V) às características valorizadas nas aulas; e VI) às perspectivas futuras na área da Educação. Essas perguntas foram elaboradas a fim de identificar o perfil de professor e de aulas que atraem e envolvem os estudantes em suas trajetórias acadêmicas.

Uma das categorias que guiam a discussão e a análise dos resultados é referente às Características e práticas docentes valorizadas pelos estudantes. As concepções de características e práticas docentes consideradas importantes podem diferir entre os professores e os estudantes. Brauer (2012) ajuda a compreender algumas características de um ensino de qualidade na universidade apontando quatro tópicos: I) estabelecer e manter uma boa relação com os estudantes; II) designar um contrato entre professor e estudantes; III) servir-se de metodologias de aprendizagem ativa; e IV) condicionar um ambiente de elevada atenção dos estudantes. Esses itens dialogam com os resultados obtidos em uma questão respondida pelos sujeitos da pesquisa, na qual precisavam classificar algumas qualidades profissionais dos professores em "pouco importante", "importante" ou "extremamente importante", conforme Quadro 1. 
Quadro 1 - Qualidades profissionais valorizadas pelos estudantes

\begin{tabular}{|c|c|c|c|}
\hline Qualidades profissionais & $\begin{array}{c}\text { Pouco } \\
\text { Importante }\end{array}$ & Importante & $\begin{array}{c}\text { Extremamente } \\
\text { importante }\end{array}$ \\
\hline Conhecimento teórico & - & $17,99 \%$ & $82,01 \%$ \\
\hline Experiência profissional & $8,63 \%$ & $51,80 \%$ & $39,57 \%$ \\
\hline Organização e planejamento & - & $10,79 \%$ & $89,21 \%$ \\
\hline Propostas inovadoras e não tradicionais & - & $19,42 \%$ & $80,58 \%$ \\
\hline Capacidade de comunicação & - & $28,78 \%$ & $71,22 \%$ \\
\hline Boa relação afetiva com os estudantes & $0,72 \%$ & $25,90 \%$ & $73,38 \%$ \\
\hline Propostas de avaliação coerentes & - & $21,58 \%$ & $78,42 \%$ \\
\hline
\end{tabular}

Fonte: Elaborado pelas autoras (2021).

Essa sistematização ilustra que a maioria dos estudantes considera todas as características citadas no Quadro 1 importantes ou extremamente importantes e, ainda que sejam valorizadas algumas características arraigadas em práticas de ensino tecnicista e tradicional, como o domínio do conteúdo, comprometimento e organização do professor, também são ressaltadas como indispensáveis algumas qualidades centradas nas relações interpessoais e práticas docentes mais voltadas à aprendizagem ativa dos estudantes. Genú (2018, p. 60) afirma que a "[...] apropriação dos conceitos fundantes de uma prática pedagógica assegura muito mais resultados satisfatórios do que o domínio de técnicas de ensino e procedimentos metodológicos". Isto é, o reconhecimento do papel social da profissão docente proporciona ao professor muito mais segurança para pensar e refletir sobre suas práticas pedagógicas do que o mero domínio das metodologias.

A docência é uma atividade feita essencialmente de relações: professor/aluno, aluno/conteúdo, professor/instituição, instituição/aluno, e é no bojo dessas relações que se dão os processos de ensino e de aprendizagem. Portanto, uma prática docente sem um positivo vínculo emocional estabelecido muito provavelmente não será uma prática significativa, mas, se houver essa ligação, as possibilidades de significação certamente serão muito maiores. Tardif e Lessard (2011, p. 35) afirmam que "[...] a docência é um trabalho cujo objeto não é constituído de matéria inerte, mas de relações humanas com pessoas capazes de iniciativa e dotadas de uma certa capacidade de resistir ou participar da ação dos professores". Considerando isso, pode-se prever que essa resistência ou participação se baseie, entre outros fatores, na relação construída entre docentes e estudantes.

Além dessas características supracitadas, os discentes apontaram outros aspectos importantes nos docentes e nas práticas desenvolvidas. Um termo muito 
utilizado pelos universitários para caracterizar as aulas nas quais mais participam e se envolvem foi "dinâmica". Os alunos apontaram que há necessidade de haver espaço para o diálogo durante as aulas. Outro estudo que se debruça sobre as metodologias utilizadas pelos professores corrobora essa ideia, afirmando que as escolhas metodológicas "[...] contribuem para a participação efetiva dos discentes como protagonistas de suas aprendizagens, uma vez que [...] os professores têm a possibilidade de ressignificar suas práticas pedagógicas" (BLASZKO; CLARO; UJIIE, 2021, p. 12).

Nesse sentido, faz-se necessária uma reflexão sobre as aulas demasiado expositivas e teóricas. Embora se entenda a necessidade de, vez ou outra, haver uma aula assim, quando se torna algo rotineiro, os estudantes já vão à universidade possivelmente desanimados. A aula expositiva tem seus benefícios para o professor, assim como o estudante também aprende com ela, mas é preciso refletir sobre seu planejamento e execução. "Assistir a aulas como se assiste a um programa de TV e dar aulas como se faz uma palestra não é mais suficiente: estamos buscando modos de em parceria - fazer aulas" (ANASTASIOU; ALVES, 2010, p. 78, grifos dos autores).

Cabe aqui, ainda, discutir um dos motivos pelos quais os estudantes não se envolvem com essas aulas. A maioria dos discentes de cursos noturnos, como é a Pedagogia da UFFS/Erechim, é composta por trabalhadores, os quais, quando chegam à universidade, estão vindo de uma jornada extensa e cansativa de trabalho. Nesse sentido, "[...] identificar as necessidades cotidianas do estudante do Ensino Superior noturno e conhecer suas inter-relações com os ambientes (sobretudo os externos à instituição de ensino) tornam-se relevantes, à medida que se visa uma formação educacional de alta qualidade" (TERRIBILI FILHO; RAPHAEL, 2009, p. 38). Não se trata, pois, de poupar os estudantes de leituras extraclasse ou então de adotar uma postura protecionista, mas sim de refletir sobre a realidade de sala de aula, buscando, entre tantos estudos e pesquisas, metodologias e estratégias que consigam manter a atenção dos estudantes, motivando-os à participação e reflexão em seu próprio processo de construção do conhecimento acadêmico.

Ainda sobre as práticas docentes, foi apontado que há necessidade de organização e planejamento prévio das aulas e leituras, diálogo entre a teoria e a prática, acolhimento, espaço para socialização de dúvidas e utilização de linguagem 
acessível, principalmente nas disciplinas introdutórias. Ademais, foram apontadas como qualidades pessoais importantes nos professores a humildade, o respeito e a empatia. Durante o curso de Pedagogia, os estudantes da UFFS/Erechim formulam ideias de uma educação com acolhimento, escuta sensível e atenta, protagonismo estudantil, práticas significativas e contextualizadas e muitos outros conceitos, portanto esperam que, nas suas aulas na universidade, vejam corporificados em seus professores os ensinamentos que constroem.

Vivenciar aulas que possibilitem refletir sobre a práxis, que envolvem os estudantes e que promovem momentos de discussão e interação sobre a profissão é um fator que contribui para a formação de professores reflexivos e que se importam com a qualidade da educação. Sendo assim, "[...] a formação de bons principiantes tem a ver, acima de tudo, com a formação de pessoas capazes de evoluir, de aprender de acordo com a experiência, refletindo sobre o que gostariam de fazer, sobre o que realmente fizeram e sobre os resultados" (PERRENOUD, 2002, p. 17).

Dessa forma, emerge a segunda categoria que guia a discussão dos resultados: Projeções dos estudantes para seus futuros profissionais. Durante o curso, os alunos vivenciam múltiplas aulas com variadas metodologias e inúmeros recursos. A partir dessas experiências, refletem e decidem o que consideram mais importante e agregam à sua prática. Nesse cenário, é imprescindível que se ensine sobre como acolher as crianças e como desenvolver um trabalho significativo, mas é ainda mais importante que se pratique isso na universidade, pois a vivência real de situações ideais é o que torna as experiências mais valorosas e mostra que é possível fazer uma educação diferente. Saber ensinar é "[...] algo que se define pelo engajamento do educador com a causa democrática e se expressa pelo seu desejo de instrumentalizar política e tecnicamente 0 seu aluno, ajudando-o a construir-se como sujeito social” (MOYSÉS, 2012, p. 14).

A partir disso, emerge uma reflexão bastante significativa no tangente às vivências proporcionadas aos estudantes ao longo da graduação em Pedagogia na UFFS/Erechim. Alguns estudantes, majoritariamente do décimo e último semestre do curso, apontaram em seus relatos que se sentem mais seguros para atuarem em determinadas áreas de atuação do pedagogo em detrimento de outras. Um estudo que se propôs a investigar sobre a atratividade da profissão docente, mais especificamente do curso de Pedagogia em uma cidade do Rio de Janeiro, também trouxe em pauta esse 
aspecto. Segundo Silva e Corrêa (2019, p. 66), "[...] no Brasil, a interação dos licenciandos com a escola é bem pequena, não sendo suficiente para prepará-los para 0 dia a dia de um docente".

Isto é uma problemática muito importante a ser refletida e discutida quando se fala em qualidade da Educação. O pedagogo é habilitado para atuar em muitas áreas educacionais, como a Educação Infantil, Anos Iniciais do Ensino Fundamental, Educação de Jovens e Adultos, Nível Médio na modalidade Normal, Gestão Escolar, Pedagogia Hospitalar, entre outros campos dentro e fora dos muros escolares. Nesse viés, pressupõe-se que, quando formado, o pedagogo tenha base teórica e metodológica para exercer sua função em qualquer uma dessas áreas, mas eles afirmam que ainda há lacunas nesse processo de formação. Visto que a Pedagogia é uma ciência bastante complexa e extensa, é possível inferir que, em quatro ou cinco anos, como é a duração média dos cursos de Pedagogia no Brasil, não há tempo hábil o suficiente para aprofundar de modo satisfatório todas as áreas de atuação do pedagogo. Podemos relacionar essa segunda hipótese com o engagement estudantil. É possível que a maneira como as aulas são ministradas pelos professores, as oportunidades de inserção no ambiente escolar e não escolar ofertadas, as propostas de reflexão e a construção do conhecimento façam com que os estudantes sintam-se mais ou menos seguros para atuar em um ou outro campo educacional.

Para que se faça uma educação de qualidade, é necessário que haja significação das experiências e conteúdos. Nessa direção, os sujeitos da pesquisa mostram-se bastante preocupados com esse aspecto e afirmam que pretendem, em suas futuras práticas, proporcionar situações significativas de aprendizagem. $\mathrm{O}$ grande número de relatos relacionados às práticas significativas aponta que, na trajetória acadêmica dos estudantes, os professores demonstraram por meio de suas aulas a importância "[...] de levar o aluno a compreender o sentido do conteúdo, qual a relação que ele tem com sua vida, com seu mundo e com a sociedade na qual está inserido" (MOYSÉS, 2012, p. 23). Dessa forma, será proporcionada uma educação de qualidade, na qual os conteúdos tratados em aula ultrapassem a utilidade escolar e perpassem pelas esferas da vida cidadã dos sujeitos.

Houve muitos estudantes que manifestaram seu profundo desejo em considerar em suas práticas o que aprenderam com seus professores na universidade. Esses 
relatos mostram que as vivências e os conhecimentos desenvolvidos ao longo da graduação foram, ou estão sendo, significativos para os alunos, fazendo com que planejem incorporá-los ao máximo nas suas práticas em futuras aulas. Além disso, alguns dos estudantes relatam que, quando entraram na universidade, começaram a interessar-se pela docência universitária.

Alguns estudantes ainda relataram que não pretendem seguir carreira docente devido aos seus atuais empregos. Esses relatos podem significar que, mesmo com uma graduação em Nível Superior, a profissão de professor não é mais viável ou financeiramente compensatória do que seus empregos atuais em outras áreas de atuação. A partir disso, pode-se inferir que, para tomar a decisão de não seguir a profissão docente, os sujeitos consideraram fatores como as condições de trabalho, a desvalorização da categoria, o salário, o sucateamento da Educação em todas as suas modalidades, entre outros elementos que circundam a vida docente. No entanto, o fato de não terem se evadido do curso ao longo dos anos demonstra que, por algum motivo, seguir os estudos na área era relevante para suas vidas.

Considerando tudo isso, está clara a importância do engagement na promoção de uma educação de qualidade. Engagement, essa palavra de origem inglesa, para a qual é possível atribuir vários significados. Segundo o Cambridge Dictionary, o vocábulo engagement está relacionado a comprometer-se com alguém, traduzindo o termo para "casamento". A palavra também aparece ligada ao interesse por algo, sendo, assim, traduzida para "engajamento". Essa segunda opção é a que se aproxima da abordagem deste estudo.

No panorama global, o engagement atrelado ao campo da educação já vem sendo estudado e abordado por diversos autores. Ao longo dos anos, o conceito foi se atualizando, conforme ilustrado no Quadro 2.

Quadro 2 - Evolução do conceito de engagement

\begin{tabular}{|c|c|c|}
\hline Tyler & Tempo na tarefa & Anos 30 \\
\hline Pace & Qualidade do esforço & Anos 60 e 70 \\
\hline Astin & Envolvimento do estudante & 1984 \\
\hline Pascarella & Resultados de aprendizagem & 1985 \\
\hline Chickering e Gamson & Boas práticas na Educação Superior & 1987 \\
\hline Tinto & Integração social e acadêmica & 1987 e 1993 \\
\hline $\begin{array}{c}\text { Kuh, Schunh, } \\
\text { Whitt e associados } \\
\text { e Kuh et al. (2005) }\end{array}$ & Engagement do estudante & 1991 e 2005 \\
\hline
\end{tabular}

Fonte: Kuh (2009 apud RIGO; VITÓRIA; MOREIRA, 2018, p. 12).

Educ. Form., Fortaleza, v. 6, n. 3, e4609, set./dez. 2021

DOI: https://doi.org/10.25053/redufor.v6i2.4609

https://revistas.uece.br/index.php/redufor/index 
No entanto, o engagement vem sendo estudado no contexto brasileiro há pouco tempo. Apesar disso, já se pode esboçar seu conceito a partir de estudos estrangeiros. O engagement, portanto, surge "[...] como uma variável que se preocupa em investigar por quais razões, por quais meios e em quais circunstâncias um indivíduo consegue desenvolver e manter uma linha de condução, um foco, um direcionamento em relação a uma pessoa, um grupo, uma atividade ou um projeto" (BRAULT-LABBÉ; DUBÉ, 2009 apud COSTA; VITÓRIA, 2017, p. 2261). Nesse sentido, observando-o no contexto universitário, é possível compreender sua importância e as contribuições de avaliá-lo como indicador de qualidade no meio acadêmico.

Ainda que não exista nenhum instrumento brasileiro para medir os aspectos que circundam o engagement, não significa que eles não sejam importantes, ou até mesmo imprescindíveis para a aprendizagem, e já é possível, com a literatura disponível, ensaiar alguns Indicadores de Qualidade a serem considerados em uma avaliação do engagement nas Instituições de Ensino Superior (IES) do Brasil. A seguir, no Quadro 2, apresentamos cinco eixos que podem orientar a avaliação do engagement nas instituições, bem como elementos que se relacionam a cada um deles.

Quadro 3 - Possíveis indicadores a serem considerados para o engagement estudantil e institucional

\begin{tabular}{|c|l|}
\hline Propostas pedagógicas & $\begin{array}{l}\text { Diz respeito às ações dos professores em sala de aula, sobre } \\
\text { suas propostas de estudo, organização de cronograma coerente } \\
\text { com o semestre no qual os estudantes se encontram, inovação } \\
\text { no planejamento e no uso de tecnologias, trabalhos } \\
\text { colaborativos, atividades estimulantes e não tradicionais, } \\
\text { avaliações coesas aos processos de aprendizagem. }\end{array}$ \\
\hline \multirow{3}{*}{ Qualidade nas relações sociais } & $\begin{array}{l}\text { Diz respeito à abertura ao diálogo entre professor e aluno, à } \\
\text { sensibilidade na resolução de problemas emergentes, ao } \\
\text { vínculo bem estabelecido na relação professor/aluno, } \\
\text { aluno/aluno, instituição/professor e institução/aluno. }\end{array}$ \\
\hline Conortunidades extraclasse & $\begin{array}{l}\text { Diz respeito às possibilidades de realização de estágios não } \\
\text { obrigatórios, grupos de estudo, projetos de pesquisa, ações } \\
\text { sociais, imersão em ambientes diferentes, intercâmbios, oferta } \\
\text { de congressos, semanas acadêmicas, entre outros. }\end{array}$ \\
\hline Condições de permanência & $\begin{array}{l}\text { Diz respeito à oferta de condições econômicas, sociais e } \\
\text { emocionais de permanência estudantil na universidade. }\end{array}$ \\
\hline Ambiente e estrutura & $\begin{array}{l}\text { Diz respeito aos espaços institucionais oferecidos aos } \\
\text { estudantes para promover o acolhimento, aconchego, opções } \\
\text { diferentes para estudo e lazer no ambiente acadêmico. }\end{array}$ \\
\hline
\end{tabular}

Fonte: Elaborado pelas autoras (2021).

O engagement, embora tenha seus "resultados finais" visíveis na qualidade da Educação Superior, envolve muito mais do que apenas a aprendizagem dos estudantes. Para que o engagement acadêmico seja promovido, mantido e elevado constantemente,

Educ. Form., Fortaleza, v. 6, n. 3, e4609, set./dez. 2021

DOI: https://doi.org/10.25053/redufor.v6i2.4609

https://revistas.uece.br/index.php/redufor/index 
é necessário que sejam combinados vários fatores, entre eles, bons processos metodológicos de aprendizagem, que mobilizem o interesse e o envolvimento dos estudantes, ações e políticas educacionais promovidas a nível institucional que possibilitem condições físicas, emocionais, sociais e financeiras para a permanência e bom rendimento dos discentes, pois, caso não haja essas condições, dificilmente um aluno terá condições cognitivas de empregar toda sua capacidade pessoal ao estudo. Além disso, também é necessário que sejam proporcionados momentos de mobilização acadêmica como um todo, a fim de que seja promovida a participação dos universitários, que se sintam pertencentes e comprometidos com a instituição.

\begin{abstract}
Sendo assim, o engajamento acadêmico emerge como uma variável de relevância a ser investigada em contextos de educação superior não apenas porque se debruça sobre aspectos cognitivos e metodológicos, envolvendo o corpo discente e docente e os processos de ensino e aprendizagem, mas porque lança um olhar investigativo sobre as instituições de ensino, focando sua organização institucional, bem como sua gestão. (VITÓRIA et al., 2018, p. 264).
\end{abstract}

Nesse sentido, incluir o engagement nos aspectos passíveis de serem considerados para a avaliação da qualidade da Educação Superior implicará, ou deveria implicar, em esforços, estudos e movimentações institucionais que o promovessem. Dessa forma, tanto docentes quanto discentes e equipe gestora se beneficiariam, pois um ambiente no qual os níveis de engagement são elevados é um espaço propício e agradável para se estar, quer seja estudando ou trabalhando.

\title{
5 Considerações finais
}

Há muito se pensava e acreditava que a aprendizagem do estudante dependia exclusivamente de sua vontade e dedicação para estudar. Entretanto, felizmente, com estudos mais aprofundados, atualmente é possível afirmar que muitos fatores contribuem positiva ou negativamente no processo de construção do conhecimento.

O presente estudo buscou compreender como o professor contribui para o engagement acadêmico no curso de Pedagogia da UFFS, campus Erechim/RS, na perspectiva de estudantes do curso. Por meio dos resultados obtidos e analisados, emergiram duas categorias descritivas: (I) Características e práticas docentes 
valorizadas pelos estudantes e (II) Projeções dos estudantes para seus futuros profissionais.

Sobre a primeira categoria, Características e práticas docentes valorizadas pelos estudantes, os resultados apontam para a importância da relação construída entre professor e estudante no decorrer dos semestres. Nesta boa relação estão contidos elementos como a flexibilidade do professor ao compreender as variáveis da vida pessoal de cada discente que possam dificultar, vez ou outra, o cumprimento do cronograma de leituras e estudos das disciplinas.

Também foi apontado que o professor precisa ter boa didática, isto é, utilizar-se de boas metodologias no desenvolvimento de suas aulas. Este é um item intrinsecamente relacionado ao engagement, pois os estudantes indicaram que se envolvem, dedicam-se e empenham-se nas disciplinas em que há promoção de discussões, trabalhos interativos, oportunidade de participação e mobilização dos conhecimentos prévios dos discentes.

Foram apontadas ainda questões referentes ao conhecimento teórico dos docentes, bem como sua organização e planejamento. Os alunos consideraram de suma importância que os docentes demonstrem em suas aulas competência sobre os assuntos tratados, bem como apresentem um planejamento organizado e coerente com as demandas da disciplina e da turma.

Foi relatado também que os professores universitários contribuem para a identificação dos alunos com determinadas áreas de atuação do pedagogo. Professores que demonstram entusiasmo, conhecimento e animação, têm experiência prática na área e apontam estratégias e metodologias para serem desenvolvidas com as crianças são apontados como ótimos profissionais, que envolvem os estudantes com o curso, bem como aproximam o interesse dos educandos por suas áreas.

Nesse sentido, pode-se inferir que os docentes têm contribuições valiosas para o engagement estudantil. Essas contribuições se dão por meio de propostas e vivências proporcionadas na universidade, desde que sejam significativas e não tradicionais. $O$ reflexo dessas contribuições é perceptível nos relatos de estudantes que entraram no curso de Pedagogia sem muito interesse pela área da educação e acabaram se envolvendo e se encontram satisfeitos com sua escolha.

Os docentes também foram citados nas Perspectivas futuras dos estudantes, segunda categoria de análise. A maioria deles - afora aqueles que não pretendem seguir 
na área da Educação, ou não definiram suas preferências ainda - aponta que quer levar para suas futuras práticas os exemplos e os conhecimentos construídos com alguns professores. Certamente essas vivências e aprendizagens foram significativas e talvez envolveram aspectos para além do cognitivo, como relações afetivas com o professor.

Com isso, constata-se que os aspectos apontados como importantes nos professores para que os estudantes envolvam-se, interessem-se e participem das aulas são elementos necessários para uma formação integral, que abranja aspectos cognitivos, sociais e emocionais. Sendo assim, os universitários apontaram que é tão importante que o professor saiba o que está ensinando, mas também é importante que saiba quem são os sujeitos que estão aprendendo. Os alunos consideram que os professores que compreendem suas vidas além-universidade, enxergando-os como sujeitos vivos, passíveis de problemas, distrações, interesses e vontades, proporcionam aulas, propostas, vivências e aprendizagens mais significativas, envolventes e, assim, promovem o engagement estudantil.

Nessa direção, a proposição de indicadores para avaliar o engagement acadêmico feita neste estudo pode contribuir para apontar elementos concretos do que é possível considerar sobre o engagement nas avaliações, auxiliando, assim, na instrumentalização dessa mudança nas IES. Por fim, retoma-se aqui que os Indicadores de Qualidade aqui propostos estão relacionados a cinco eixos, sendo eles: I) propostas pedagógicas; II) qualidade das relações sociais; III) oportunidades extraclasse; IV) condições de permanência; e V) ambiente e estrutura.

\section{Referências}

ANASTASIOU, L. G. C.; ALVES, L. P. Estratégias de ensinagem. In: ANASTASIOU, L. G. C.; ALVES, L. P. (org.). Processos de ensinagem na universidade: pressupostos para as estratégias de trabalho em aula. 9. ed. Joinville: Univille, 2010. p. 73-107.

BARDIN, L. Análise de Conteúdo. São Paulo: Almedina, 2016.

BLASZKO C. E.; CLARO, A. L. A.; UJIIE, N. T. A contribuição das metodologias ativas para a prática pedagógica dos professores universitários. Educação \& Formação,

Fortaleza, v. 6, n. 2, p. e3908, 2021. DOI: 10.25053/redufor.v6i2.3908. Disponível em: https://revistas.uece.br/index.php/redufor/article/view/3908. Acesso em: 26 maio 2021. 
BRAUER, M. Ensinar na universidade: conselhos práticos, dicas, métodos pedagógicos. São Paulo: Parábola, 2012.

CAMBRIDGE DICTIONARY. Engagement. Cambridge Dictionary. Disponível em: https://dictionary.cambridge.org/pt/dicionario/ingles/engagement. Acesso em: 26 maio 2021.

COSTA, P. T.; VITÓRIA, M. I. C. Engajamento acadêmico: aportes para os processos de avaliação da educação superior. In: CONGRESSO NACIONAL DE EDUCAÇÃO EDUCERE, 8., 2017, Curitiba. Anais [...]. Curitiba: PUC-PR, 2017.

FREIRE, P. Pedagogia da autonomia: saberes necessários à prática educativa. São Paulo: Paz e Terra, 2011.

GENÚ, M. S. A abordagem da ação crítica e a epistemologia da práxis pedagógica. Educação \& Formação, Fortaleza, v.3, n. 9, p. 55-70, 2018. Disponível em: https://revistas.uece.br/index.php/redufor/article/view/856/758. Acesso em: 26 maio 2021.

GIL, A. C. Métodos e técnicas de pesquisa social. 6 ed. São Paulo: Atlas, 2008.

LIMA, T. C. S.; MIOTO, R. C. T. Procedimentos metodológicos na construção do conhecimento científico: a pesquisa bibliográfica. Katálysis, Florianópolis, v. 10, n. esp., p. 37-45, 2007. Disponível em:

http://www.scielo.br/scielo.php?script=sci arttext\&pid=s1414-49802007000300004.

Acesso em: 25 mar. 2019.

LÜDKE, M.; ANDRÉ, M. E. D. A. Pesquisa em educação: abordagens qualitativas. 2. ed. São Paulo: EPU, 2017.

MCEWAN, E. K. Ten traits of highly effective teachers: how to hire, coach, and mentor successful teachers. Thousand Oaks: Corwin, 2002.

MOYSÉS, L. M. O desafio de saber ensinar. 16. ed. Campinas: Papirus, 2012.

PERRENOUD, P. A prática reflexiva no ofício do professor: profissionalização e razão pedagógica. Porto Alegre: Artmed, 2002.

RIGO, R. M.; VITÓRIA, M. I. C.; MOREIRA, J. A. Engagement acadêmico: retrospectiva histórica (diferentes níveis, distintas consequências e responsabilidades). In: RIGO, R. M.; MOREIRA, J. A.; VITÓRIA, M. I. C. (org.). Promovendo o engagement estudantil na educação superior: reflexões rumo a experiências significativas e integradoras na universidade. Porto Alegre: PUC-RS, 2018. p. 15-35.

SILVA, K. F. M.; CORRÊA, C. P. Q. Atratividade docente entre os ingressantes no curso de Pedagogia. Educação \& Formação, Fortaleza, v. 5, n. 13, p. 59-78, 2020. Disponível em: https://revistas.uece.br/index.php/redufor/article/view/1468/1902. Acesso em: 26 maio 2021. 
TARDIF, M.; LESSARD, C. O trabalho docente: elementos para uma teoria da docência como profissão de interações humanas. 6. ed. Petrópolis: Vozes, 2011.

TERRIBILI FILHO, A.; RAPHAEL, H. S. Ensino Superior noturno: problemas, perspectivas e propostas. Marília: Fundepe, 2009.

VITÓRIA, M. I. C. et al. Engajamento acadêmico: desafios para a permanência do estudante na Educação Superior. Educação, Porto Alegre, v. 41, n. 2, p. 262-269, 2018. Disponível em: http://revistaseletronicas.pucrs.br/ojs/index.php/faced/article/view/27960. Acesso em: 29 jun. 2019.

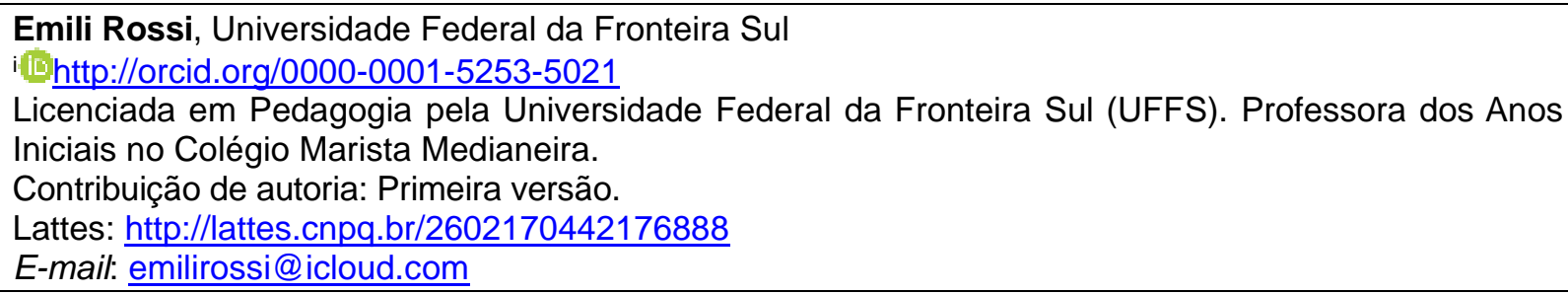

Zoraia Aguiar Bittencourt, Universidade Federal da Fronteira Sul, Programa de Pós-Graduação Profissional em Educação, Curso de Pedagogia

ii (IDttps://orcid.org/0000-0002-1290-8847

Doutora e mestra em Educação, especialista em Alfabetização e licenciada em Letras. Professora do Programa de Pós-Graduação Profissional em Educação (PPGPE), do Programa de Pós-Graduação Interdisciplinar em Ciências Humanas (PPGICH) e do curso de licenciatura em Pedagogia da Universidade Federal da Fronteira Sul (UFFS), campus Erechim, Rio Grande do Sul.

Contribuição de autoria: Supervisão.

Lattes: http://lattes.cnpq.br/9415905395080587

E-mail: zoraiabittencourt@gmail.com

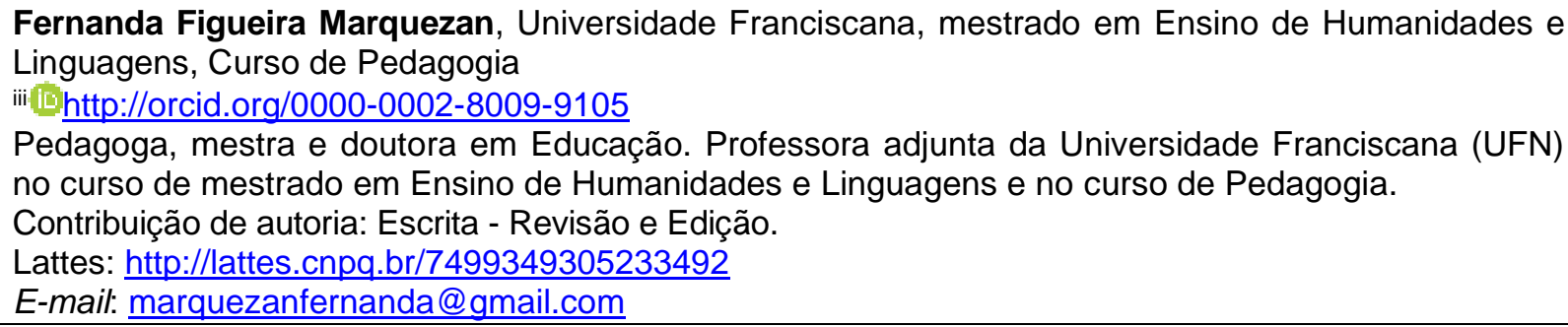

Fernanda Figueira Marquezan, Universidade Franciscana, mestrado em Ensino de Humanidades e Linguagens, Curso de Pedagogia iii $h$ ttp://orcid.org/0000-0002-8009-9105

Pedagoga, mestra e doutora em Educação. Professora adjunta da Universidade Franciscana (UFN) no curso de mestrado em Ensino de Humanidades e Linguagens e no curso de Pedagogia.

Contribuição de autoria: Escrita - Revisão e Edição.

Lattes: http://lattes.cnpq.br/7499349305233492

E-mail: marquezanfernanda@gmail.com

Editora responsável: Lia Machado Fiuza Fialho Pareceristas ad hoc: Maria Almeida e Mário Azevedo

\section{Como citar este artigo (ABNT):}

ROSSI, Emili; BITTENCOURT, Zoraia Aguiar; MARQUEZAN, Fernanda Figueira. As contribuições do professor universitário para o engagement acadêmico. Educ. Form., Fortaleza, v. 6, n. 3, e4609, 2021. Disponível em: https://revistas.uece.br/index.php/redufor/article/view/4609 


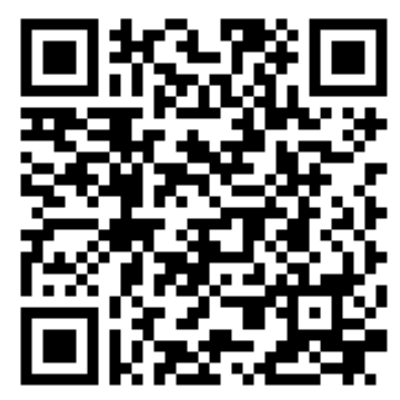

Recebido em 14 de janeiro de 2021. Aceito em 20 de abril de 2021.

Publicado em 7 de julho de 2021. 